\title{
Marketing social e digital do Ministério da Saúde no Instagram: estudo de caso sobre aleitamento materno
}

\author{
Social and digital marketing of the Brazilian Ministry of Health on \\ Instagram: a case study of breast-feeding \\ Marketing social y digital del Ministerio de Salud brasileño en el Instagram: \\ estudio de caso sobre lactancia
}

\author{
Pâmela Araujo Pinto ${ }^{1, a}$ \\ pinpamela@gmail.com | http://orcid.org/0000-0002-9699-7073 \\ ${ }^{1}$ Ministério da Saúde, Assessoria de Comunicação. Rio de Janeiro, RJ, Brasil. \\ a Doutorado em Comunicação pela Universidade Federal Fluminense.
}

\section{Resumo}

Este artigo mapeia as estratégias de atuação do Ministério da Saúde na rede social Instagram. Realizou-se um estudo de caso no período de agosto de 2017 a agosto de 2018 para verificar como o tema da amamentação foi abordado na rede oficial do governo brasileiro para saúde. O corpus tem 65 posts sobre a questão, que foram analisados considerando as métricas de monitoramento das redes sociais: alcance; volume; atividade; engajamento dos usuários e influência do conteúdo junto aos seguidores. Analisando as estratégias de atuação do marketing social e digital identificou-se a falta de interação e resposta aos usuários e a baixa diversidade de representação das mulheres. O levantamento aponta a necessidade de problematizar as práticas do Ministério nesta rede e propor melhorias para ampliar o diálogo com a sociedade.

Palavras-chave: Marketing social; Marketing digital; Ministério da Saúde; Aleitamento materno; Redes sociais; Instagram. 


\begin{abstract}
This article maps out the strategies of performance of the Brazilian Ministry of Health in Instagram's social network. A case study was carried out in the period from August 2017 to August 2018 to verify how the topic of breast-feeding was approached in the official network of the Brazilian government for health. The corpus has 65 posts about that issue which were analised considering the measures to monitor social networks: scope, volume, activity, user engagement and influence of the content on the followers. Analyzing the strategies of social and digital marketing used by the Brazilian government for health, it was identified the lack of interaction with users and of response to them and the low diversity of women represented on its Instagram profile. The research points out that we need to problematize Ministry practices in this network and to propose improvements to broaden the dialogue with the society.
\end{abstract}

Keywords: Social marketing; Digital marketing; Ministry of Health; Breast-feeding; Social networks; Instagram.

\title{
Resumen
}

El artículo mapea las estrategias de actuación del Ministerio de Salud de Brasil en la red social Instagram. Se realizó un estudio de caso en el período de agosto de 2017 hasta agosto de 2018 para escudriñar como se abordó el tema de la lactancia en la red oficial del gobierno brasileño para salud. El corpus tiene 65 posts a respecto del asunto y fueron estudiados considerando las medidas para monitorizar redes sociales: alcance; volumen; actividad; interacción de los usuarios e la influencia del contenido en los seguidores. Analizando las estrategias de actuación del marketing social y digital se identificó falta de interactividad, usuarios sin respuesta y la baja diversidad de representación de las mujeres en lo perfil del gobierno brasileño en Instagram. La investigación apunta la necesidad de problematizar las prácticas del Ministerio en esta red y de proponer mejorías para ampliar el diálogo con la sociedad.

Palabras clave: Marketing social; Marketing digital; Ministerio de Salud; Lactancia; Redes sociales; Instagram.

\section{Contribuição dos autores:}

Concepção e desenho do estudo: Pâmela Araujo Pinto

Aquisição, análise ou interpretação dos dados: Pâmela Araujo Pinto

Redação do manuscrito: Pâmela Araujo Pinto

Revisão crítica do conteúdo intelectual: Pâmela Araujo Pinto

Declaração de conflito de interesses: não há.

Fontes de financiamento: não há.

Considerações éticas: a autora não trabalha no setor de mídias digitais do Ministério da Saúde e portanto se considera apta a fazer uma reflexão direta sobre a temática do artigo.

Agradecimentos/Contribuições adicionais: não há.

Histórico do artigo: submetido: 07 nov. 2018 | aceito: 01 ago. 2019 | publicado: 20 dez. 2019.

Apresentação anterior: não houve.

Licença CC BY-NC atribuição não comercial. Com essa licença é permitido acessar, baixar (download), copiar, imprimir, compartilhar, reutilizar e distribuir os artigos, desde que para uso não comercial e com a citação da fonte, conferindo os devidos créditos de autoria e menção à Reciis. Nesses casos, nenhuma permissão é necessária por parte dos autores ou dos editores. 


\section{Introdução}

Este artigo tem o objetivo de analisar a presença do Ministério da Saúde (MS) no Instagram como estratégia de marketing social e digital, tendo em vista que o órgão se propõe a promover a saúde, além de estimular a adesão às campanhas. Em 2019, o Ministério soma sete redes sociais ativas. O canal de diálogo mais antigo, em uso, com os cidadãos é o Facebook - do qual começou a participar em 2008. Para entender as ações do órgão no Instagram, foi feito um estudo de caso sobre um tema de relevância para saúde pública, a amamentação. Este assunto afeta o principal perfil de usuários desta rede de compartilhamento de imagens, as mulheres. Elas constituem 60\% dos usuários

Ainternetéumainterfacenecessária nos estudos de comunicaçãoe saúde ${ }^{2}$, tendo em vista quea redeéa segunda mídia mais usada pelos brasileiros, ficando atrás apenas da televisão. Há cerca de 116 milhões de conectados no país, de acordo com o Instituto Brasileiro de Geografia e Estatística (IBGE) na sua Pesquisa Nacional por Amostra de Domicílios (PNAD)3 de 2016 - mesmo diante do descompasso de acesso em diferentes regiões geográficas. O brasileiro passa em média cinco horas nesta rede ${ }^{4}$. O acesso ocorre preferencialmente pelos celulares. O país conta com cerca de 265,3 milhões de aparelhos. Considerando a importância crescente desta mídia na vida dos brasileiros, selecionou-se o Instagram, fenômeno planetário para expressão da cultura no ambiente digital por meio de imagens, para entender como o diálogo do MS sobre a saúde é feito com a sociedade.

A metodologia utilizada foi um estudo de caso do perfil do Ministério da Saúde no Instagram, entre agosto de 2017 e de 2018. A coleta de dados selecionou todas as publicações sobre aleitamento materno postadas pelo órgão neste intervalo. O monitoramento ocorreu nesse período por contemplar a sanção da lei Agosto Dourado (n ${ }^{0}$ 13.435/2017) , criada para definir o Mês do Aleitamento Materno. Este estudo correlacionou conceitos de marketing social e digital para analisar o conteúdo à luz das métricas de monitoramento de redes sociais: alcance; volume; atividade; engajamento e influência. Tais métricas possibilitaram observar o conteúdo postado e a interação com os seguidores, o que permitiu uma análise de aspectos qualitativos e quantitativos da amostra. Também foi feita uma pesquisa bibliográfica sobre amamentação, a partir do olhar da comunicação e saúde.

O corpus da pesquisa é formado por 65 posts do MS sobre a temática. Foram observadas as interações como curtidas, visualizações de vídeos, comentários, marcações e o diálogo com o MS. Entre 2017 e 2018 o conteúdo das postagens foi semelhante e versou sobre estímulo ao aleitamento; problemas ao amamentar; como amamentar; Agosto Dourado; doação do leite/bancos de leite; dúvidas de mães de primeira viagem; eventos no Facebook com especialistas; a importância da amamentação para a nutrição; mitos sobre amamentação; campanha de amamentação do MS; redução da mortalidade infantil.

É verificado como o Ministério da Saúde se apropriou das estratégias de marketing social e digital para se relacionar com um público segmentado, mães e mulheres. O órgão conseguiu mobilizar este perfil de usuárias e gerar advogados da instituição? - um dos principais objetivos do marketing feito nas redes. Como foi feito o diálogo com este perfil de usuárias do Sistema Único de Saúde (SUS)?

$\mathrm{O}$ artigo está dividido em quatro partes. Na primeira, abordaram-se os conceitos de marketing social e digital para iniciar um diálogo com comunicação e saúde. No segundo tópico, foi exposta a presença do Ministério da Saúde nas redes sociais, com ênfase no Instagram. A terceira parte traz a análise sobre amamentação na referida rede. Por fim, são expostas as considerações finais.

\section{Marketing social e digital: uma apropriação para saúde}

Neste tópico, serão apresentados os conceitos de marketing social e digital e a interação destes com a área da comunicação e saúde. Essa aproximação é criticada por alguns autores, mas neste artigo busca-se ampliar esse debate, reconhecendo a relação crescente entre cidadãos e a internet. 
O marketing social usa técnicas mercadológicas do marketing e as aplica na promoção de uma causa, ideia ou comportamento social 6 . O termo vem sendo usado desde a década de 1970 como ferramenta para controle de programas voltados à adesão de grupos em diferentes projetos voltados para a sociedade. As campanhas de uso de preservativo no carnaval para evitar a transmissão de infecções sexualmente transmissíveis são apontadas como casos práticos dessa adoção de estratégia de marketing.

Schneider e Luce $^{7}$ realizaram uma pesquisa bibliográfica sobre as reconfigurações do conceito de marketing social ao longo dos anos e identificaram o amadurecimento desta área de estudo. Os autores mapearam leituras que atrelam o seu surgimento como um contraponto a diversos acontecimentos da década de 1960, nos EUA, inclusive à própria ideia consumismo. O marketing foi percebido também como um aliado da sociedade, usado para fins não lucrativos, e não apenas como difusor de consumo. Eles apontam uma nova etapa da agenda de pesquisa do marketing social, mais consolidada conceitualmente, com o objetivo de alcançar o bem-estar social. Para os autores, o marketing social se diferencia de outros conceitos como a própria ideia de responsabilidade social corporativa, pois é feito por organizações não empresariais, enquanto a outra modalidade é feita por empresas com fins lucrativos.

Kunsch ${ }^{6}$ destaca o interesse público do marketing social, direcionado para mudança nas práticas sociais. A partir de estímulos desse tipo de marketing são realizadas mudanças no comportamento, de valores e também cognitivas 7 . Elas sugerem a adoção de novas práticas em relação ao corpo, à natureza e à sociedade.

Em mapeamento de pesquisas feitas sobre o marketing social no Brasil, na última década, Paula e outros $^{8}$ constataram que a saúde é uma das áreas privilegiadas nesses estudos, pois $25 \%$ da amostra (oito artigos) exploraram a relação do marketing social e saúde. Essa tendência segue o cenário internacional, no qual temas de saúde pública mobilizam investigações no âmbito do marketing e da sociedade ${ }^{7,8}$.

Araújo e Cardoso ${ }^{2}$ problematizam essa persuasão do marketing social por considerarem que as estratégias reforçam um pressuposto comportamental desenvolvimentista, no qual os problemas de saúde são causados por atitudes dos indivíduos. Contudo, o cenário das redes sociais, pode ser uma oportunidade para tornar essa linha de ação comunicativa mais dialógica. A interação é um pressuposto para a presença das instituições na rede. O engajamento propiciado pelas novas redes é estratégico para ampliar o conhecimento sobre a saúde, sobre campanhas e tornar o cidadão mais consciente da sua saúde e da sociedade na qual está inserido. As redes empoderam cidadãos ${ }^{9}$, que passam a se organizar em grupos de afinidades e buscar ativamente informações do seu interesse, inclusive sobre saúde.

O MS é o órgão responsável pela saúde pública no Brasil, sem fins lucrativos, e empreende estratégias de relacionamento com a sociedade para promover a saúde e o SUS. A sua presença no Instagram pode ser considerada uma atividade de marketing social. O Ministério promove orientação sobre saúde com objetivo de mudar comportamentos dos seguidores para adoção de práticas saudáveis. Na matéria de lançamento do seu perfil no Instagram, o órgão informou a sua função: "A mídia social de fotos será utilizada para mobilizar os usuários na divulgação de campanhas e ações do Ministério durante todo o ano"”o

Como a ação do MS está sendo feita nas redes sociais, podemos incluir o adendo digital a esse tipo de estratégia de comunicação e analisar os conteúdos postados sob o novo olhar recebido pelo marketing digital: o Marketing 4.o, produzido para usuários interconectados na rede. Este novo estágio do marketing apontado por Kotler11 tem como objetivo promover a ação e a defesa da marca, impactando não apenas os seguidores na internet, mas fora das redes. As regras desse relacionamento entre marcas e pessoas, em tempos de hiperconexão, valem para o marketing social. Empresas/órgãos e consumidores andam lado a lado e o lucro (ou o alcance da mensagem e possível mudança de conduta) é resultado da valorização das pessoas. As instituições precisam incluir as demandas dos seus clientes/membros nos produtos e serviços que ofertam.

O cidadão/consumidor/usuário também produz conteúdo nas redes, comenta, critica as instituições com as quais se relaciona. Ele deve ser incluído como coparticipante na produção de interações e conteúdos produzidos pelas instituições na internet. Não há mais uma relação de passividade ao receber informações 
e propagandas, pois as pessoas decidem para quais 'marcas' vão dar atenção nas horas de conexão. A rede aproxima os atores do marketing social e o contato gerado por essa aproximação é alavancado com conteúdo de qualidade, interessante à rotina dos indivíduos - esta estratégia é chamada de marketing de conteúdo. Assim, é importante manter os canais de contato atualizados para garantir uma comunicação rápida, pois o diálogo ocorre todos os dias da semana. É preciso ouvir as necessidades e desejos dos seguidores para contemplar suas demandas na produção de informações e campanhas ${ }^{11}$.

Nesses espaços, as instituições precisam assumir características humanas para iniciar uma relação de cumplicidade. A meta é converter os seguidores em advogados da marca ${ }^{11}$, que irão defendê-la e recomendá-la. No caso do MS, irão aderir às práticas de promoção da saúde, prevenção e campanhas. Essa relação horizontal é uma demanda tanto no âmbito da comunicação mercadológica como da comunicação institucional. Permite monitorar em tempo real a eficiência das ações, por meio de indicadores produzidos nas diferentes redes. Pode ser direcionada para perfis determinados (por gênero, idade, localização) com uso de postagens patrocinadas (pagas pelo dono do perfil). Isso permite a adaptação de estratégias adotadas, em tempo real, para obter maior adesão e engajamento.

O conteúdo produzido pelo MS nas plataformas online está balizado pelo Manual de Orientação para Atuação em Mídias Sociais da Secretaria de Comunicação da Presidência da República (atual Secom - Secretaria Especial de Comunicação Social). O documento está alinhado com estratégias de marketing digital e normatiza a criação e gestão de redes sociais por órgãos federais. Tem como diretrizes básicas a produção de conteúdo institucional sobre ações do governo, somada ao conteúdo vivo, que inclui temas relevantes ao cotidiano da população e também conteúdo de utilidade pública, com informações sobre serviços. Essas informações são expostas com um tom de caráter oficial, no qual tudo que é divulgado é considerável verdade incontestável ${ }^{12}$.

O manual foi lançado em 2012 e, desde então, vem sendo atualizado. Valoriza a interação com o cidadão, por considerar que a troca de informações é a essência dessas plataformas de comunicação nas redes: "A falta de resposta do órgão público para os cidadãos pode gerar uma má interpretação pelos cidadãos. A interatividade é um recurso indispensável para que se alcancem os resultados esperados pela comunicação que acontece no ambiente de mídias sociais. [...] Agradeça qualquer tipo de participação, com postura educada, seja uma crítica, sugestão ou elogio. [...] Responder aos comentários e às perguntas recebidas é a base para a construção de um relacionamento nas redes. Para isso, a interação deve ser contínua e não deve se restringir apenas a momentos de crises institucionais ou de imagem”².

A partir da apropriação da ideia de marketing social e digital vamos analisar o perfil do Ministério da Saúde, seu conteúdo, as interações feitas com a sociedade. O estudo de caso apresentado a seguir analisou o conteúdo dentro de critérios de monitoramento para ações em redes sociais (alcance; volume; atividade; engajamento e influência).

\section{Ministério da Saúde nas redes sociais e o relacionamento no Instagram}

Há cerca de uma década, o Ministério da Saúde utiliza formalmente as redes sociais como canal de comunicação para disseminação de conteúdos, informações e campanhas. Atualmente, ele está em sete redes sociais ativas: Facebook, Twitter, Flickr, Blog da Saúde, Youtube, Slideshare e Instagram. Antes do Facebook, interagiu com internautas no Orkut, extinto em 2014.

O Facebook é a rede mais antiga em uso pelo MS, e seu perfil foi criado em 2008, antes mesmo da elaboração do guia da Secom. É a rede em que o Ministério tem o maior número de seguidores: dois milhões de pessoas. Traz conteúdo de outras redes sociais do órgão no perfil e usa vídeos, fotos e textos para interagir. Informa que sua missão é a "Qualificação do SUS por meio do diálogo com a população"13. Em 2009, foi criado seu perfil no Twitter, tendo como primeiro tema a Pandemia Influenza A (H1N1). Contabiliza 654 mil seguidores e cerca de 10 mil curtidas. A página oficial do órgão já publicou mais de 129 mil tweets em dez anos. No mesmo ano passou a ser usuário do Flickr, que funciona como um repositório de fotos, com 72 mil imagens de ações da pasta. A criação do Blog da Saúde pelo MS e o início da participação do órgão 
no Youtube se deram em 2011. O blog é hospedado no portal do Ministério da Saúde e publica matérias sobre saúde e conteúdo institucional. Também disponibiliza espaço para as redes Facebook e Twitter. Descreve-se com a missão de levar mais informações ao cidadão e estabelecer um diálogo mais aberto com a sociedade. O perfil no Youtube tem 43 mil inscritos e soma 22 milhões de visualizações em vídeos e campanhas de saúde. Em 2013, foi criado seu perfil mais recente, no Instagram. Nele, até setembro de 2018, tinha cerca de cinco mil publicações e 285 mil seguidores. A primeira campanha abordada foi a do carnaval, com hashtags sobre prevenção do HIV.

O Instagram foi criado em 2010 e tem como ação principal a postagem de fotos e vídeos exclusivamente pelo celular. "Permite que seus usuários criem um perfil, façam uma foto ou vídeo, escolham um filtro para mudar sua aparência e publiquem. A plataforma permite, ainda, o compartilhamento do conteúdo com demais redes como o Facebook, o Twitter, entre outros" ${ }^{\prime 2}$. Nesta rede é possível incluir uma postagem na galeria de imagens que forma o chamado feed (página principal) e nas stories - espaço criado em 2016 como uma possibilidade de publicar textos, fotos ou vídeos de modo mais efêmero, com 24 horas de exibição, sem entrar no feed. Os destaques são espaços criados para armazenar as stories de maneira contínua, para que possam ser visualizadas posteriormente, na página inicial do perfil. Em 2018, foi criada a TV Instagram para reproduzir vídeos mais longos. Por meio desta função, pode ser feita transmissão de vídeos em tempo real. Além das imagens, é possível adicionar textos, emojis, stickers e marcações de hashtags. A interação entre os usuários é feita por meio de likes (curtidas), de comentários, repostagens e diálogos por mensagens diretas (direct messages). Em computadores do tipo desktop a interação é limitada, permite apenas acompanhar o conteúdo e fazer comentários.

Em agosto de 2018, a rede informou, inicialmente, ter 800 milhões de usuários ativos por mês. Dois meses depois informou ter mais um bilhão de usuários ativos ${ }^{14}$. Por dia, são mais de 500 milhões de usuários e tem mais de 400 milhões de compartilhamentos de stories $^{15}$. O Brasil contabiliza cerca de 50 milhões de usuários nessa rede. Na Apple Store, loja de aplicativos do sistema operacional dos aparelhos Iphone, ocupa o $4^{\circ}$ lugar entre os aplicativos gratuitos mais baixados. Na Play Store, ambiente para baixar e comprar aplicativos do sistema operacional Android, é o terceiro aplicativo mais baixado. Os dados citados acima são referentes a outubro de 2018.

Lemos e de Sena ${ }^{1}$ consideram o aplicativo um fenômeno planetário, sendo uma das mais fortes expressões da cultura do entretenimento digital, baseada em uma cultura de narrativas íntimas, cotidianas ${ }^{16} \mathrm{e} \mathrm{no} \mathrm{forte} \mathrm{consumo}$ de imagens. Tem nas mulheres jovens um amplo público: 51\% das usuárias têm entre 18 e 29 anos e 71\% têm curso superior ou pós-graduação. Essa rede se torna um espaço privilegiado para acompanhar as discussões sobre amamentação promovida pela principal referência oficial em saúde no Brasil, o perfil do Ministério.

A matéria de lançamento do perfil do MS no Instagram ${ }^{17}$ falou que "serão postadas fotos lúdicas, mensagens sobre a campanha para que todos os internautas se engajem e participem também com fotos usando a hashtag \#usecamisinha e \#camisinhanafolia. A mídia social de fotos será utilizada para mobilizar os usuários na divulgação de campanhas e ações do Ministério durante todo o ano" ${ }^{\text {". }}$ O texto explica que as redes do órgão atuam no diálogo e na aproximação do governo federal com a sociedade. No caso específico do Instagram, o Ministério explica o tipo de conteúdo que será usado: "as informações divulgadas são ações de saúde pública que auxiliam na melhoria da qualidade de vida do cidadão, seja para a promoção da saúde, prevenção de doenças ou adesão da população às mobilizações de campanhas"”o .

O feed, página inicial do Instagram, do MS é formado por fotos, vídeos e cards (imagens com textos). Contém a Instagram TV e os destaques de stories sobre Vacina, Período Eleitoral, Doação de Leite e Sangue e HIV/Aids. Notou-se que o MS utiliza todos os canais de inserção de conteúdo do aplicativo. Os temas presentes nas postagens são campanhas de saúde (HIV/doação de sangue); prevenção de doenças; alimentação saudável; datas da saúde; datas comemorativas; maternidade/paternidade; vacinação; bemestar, além de conteúdo institucional. A Figura 1 aponta a página inicial do Ministério da Saúde no aplicativo. 


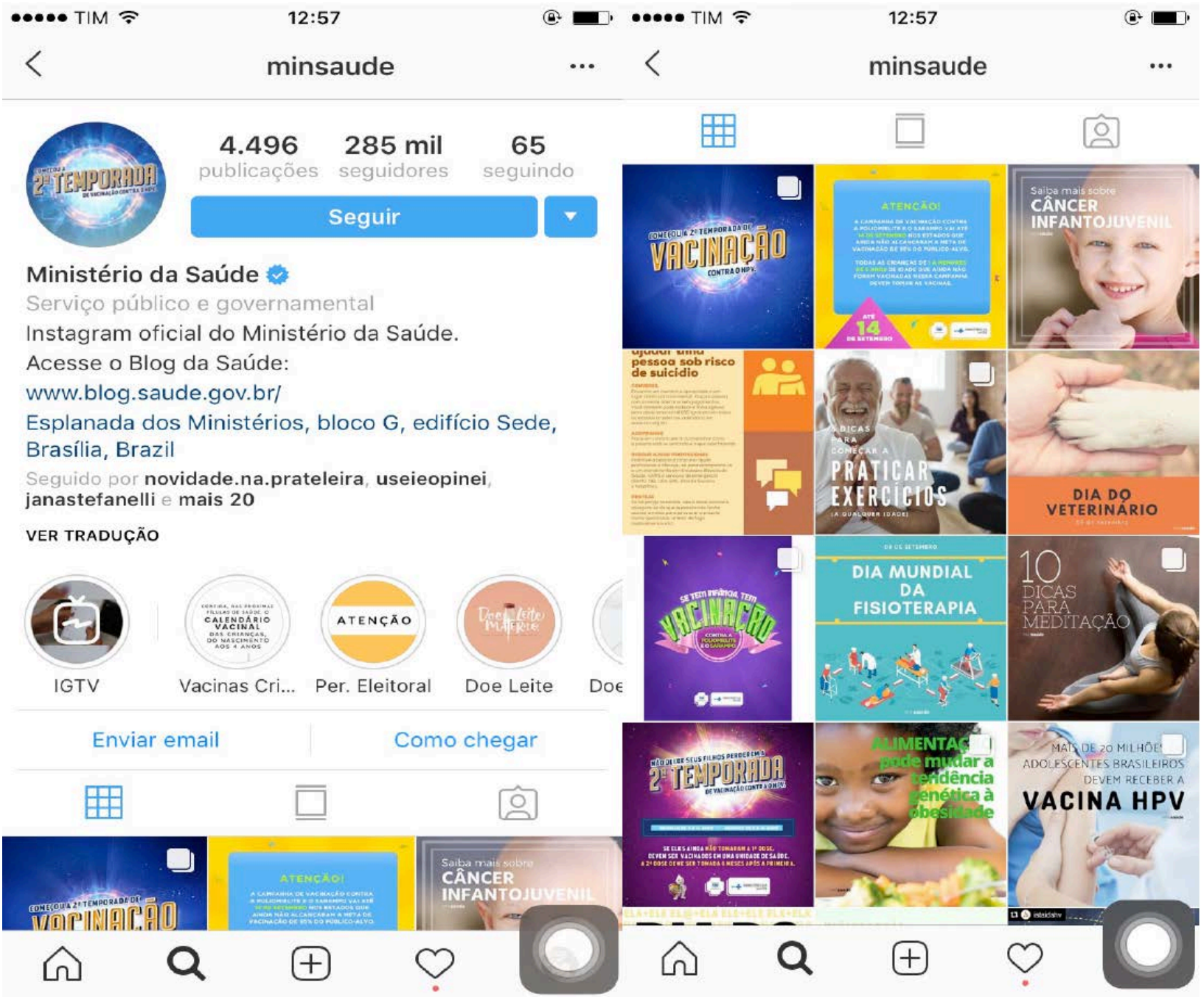

Figura 1 - Feed do Instagram do Ministério da Saúde (Setembro/2018)

Fonte: Instagram do Ministério da Saúde ${ }^{17}$ (Setembro, 2018).

O próximo item destacará a análise de conteúdo feita sobre o tema amamentação na rede social do Ministério da Saúde. Ela resulta do estudo de caso feito para compreender as ações do órgão, balizadas pelas estratégias de marketing social e digital.

\section{Estudo de caso: amamentação no Instagram do Ministério da Saúde}

O aleitamento materno ocorre "quando a criança recebe leite materno diretamente da mama ou ordenhado, ou leite humano de outra fonte, independentemente de receber ou não outros alimentos"18.

Cabe destacar que, neste estudo de caso, o olhar para o conteúdo publicado no Instagram do Ministério da Saúde considera o papel do órgão no fortalecimento da Política Nacional de Promoção, Proteção e Apoio ao Aleitamento Materno no país. Além de valorização do tema no SUS, com a promoção da saúde, a preparação de profissionais de saúde na educação continuada, o MS é um ator para consolidar os objetivos da política. Dentre eles destacam-se dois que se referem diretamente à sua ação de marketing social e digital e de comunicação pública: a proteção do aleitamento materno frente ao agressivo marketing comercial de produtos industrializados que competem com a amamentação; a produção e a difusão de conhecimentos sobre aleitamento materno para a sociedade.

OInstagraméaprincipal rededecompartilhamentodeimagens destemomento, usadapredominantemente por mulheres tendo em vista que 60\% dos usuários são mulheres ${ }^{1}$. É um espaço importante para verificar as estratégias de interação do Ministério da Saúde nas redes sociais. Ela vai contrabalancear as constantes 
sugestões de conteúdo das marcas de alimentação voltadas para crianças, feitas nas redes sociais das empresas e de influenciadores digitais (sobre maternidade e de profissionais de saúde).

A metodologia utilizada neste artigo foi um estudo de caso do perfil do Ministério da Saúde no Instagram, com ênfase no tema de amamentação. Foi feita uma análise do conteúdo coletado e uma leitura dos dados qualitativos e quantitativos à luz das ações de marketing social e digital, com ênfase na perspectiva do Marketing 4.o. Esta estratégia aponta que os internautas também são produtores de conteúdo e interagem com frequência entre si, por meio de comunidades virtuais, e com entidades que representam assuntos do seu interesse ${ }^{11}$. Também foi feita uma pesquisa bibliográfica sobre amamentação, a partir do olhar da comunicação e saúde.

A coleta de dados foi feita em setembro de 2018 e considerou todos os posts sobre aleitamento publicados no perfil do MS entre agosto de 2017 e agosto de 2018. Este recorte temporal foi escolhido por contemplar a sanção da lei Agosto Dourado ( $\mathrm{n}^{0}$ 13.435/2017) para definir o mês do Aleitamento Materno. Formou-se um corpus com 65 posts e cada publicação foi analisada quanto ao seu conteúdo e a partir das interações com os seguidores (curtidas, visualizações de vídeos, comentários e marcações). As métricas de monitoramento de redes sociais adotadas foram: alcance; volume; atividade; engajamento e influência ${ }^{20-22}$.

a) Alcance mensura a capacidade de disseminar conteúdo do perfil a partir de indicadores de números de visualização, seguidores, visitantes;

b) Volume refere-se à quantidade de informação gerada e armazenada na mídia;

c) Atividade observa a frequência das atualizações;

d) Engajamento aponta a participação dos seguidores no perfil, sinalizando a relação do número de seguidores e ações de curtidas, visualizações e comentários;

e) Influência refere-se à relevância da mídia social na internet.

Tais métricas possibilitaram uma análise de aspectos qualitativos (diálogo entre os seguidores com o MS) e quantitativos (números de interações) da amostra.

A amostra identificou 32 posts publicados em quatro meses de 2017. Eles contemplaram os temas: estímulo à amamentação; problemas ao amamentar; como amamentar; Agosto Dourado; doação do leite/bancos de leite; dúvidas de mães de primeira viagem; eventos no Facebook com especialistas; a importância da amamentação para a nutrição; mitos sobre amamentação; campanha amamentação de 2017; redução da mortalidade infantil. Em 2018, foram mapeadas 33 postagens, presentes em seis meses. Os temas foram semelhantes: estímulo à amamentação; doação do leite materno; como amamentar; problemas ao amamentar; benefícios da amamentação; repost de celebridades amamentando; campanha de amamentação de 2018; nutrição e amamentação; vacina para lactantes. Cabe destacar que naquele ano houve um desequilíbrio da temática, com $45 \%$ dos posts (15) sobre a doação do leite. Nos dois anos, as fotos predominaram sobre os vídeos. O Quadro 1 sintetiza os indicadores mapeados.

Quadro 1-Amostra sobre amamentação no Instagram do MS

\begin{tabular}{|l|l|l|}
\hline Amostras & $\mathbf{2 0 1 7}$ & $\mathbf{2 0 1 8}$ \\
\hline Posts & 32 & 33 \\
\hline Meses & $\begin{array}{l}4 \text { (agosto, setembro, outubro e } \\
\text { dezembro) }\end{array}$ & $\begin{array}{l}6 \text { (fevereiro, março, maio, junho, julho } \\
\text { e agosto) }\end{array}$ \\
\hline Curtidas das fotos (total) & 30,3 mil & 33,4 mil \\
\hline Média de curtida por post & 948 curtidas & 1.013 \\
\hline Visualizações de vídeos (total) & 10 mil & 18,3 mil \\
\hline Comentários & 517 & 774 \\
\hline
\end{tabular}

Fonte: A autora (2018). 
O alcance do perfil do MS sobre o tema recortado ainda é baixo, considerando que é a principal fonte oficial sobre saúde. Apesar de somar 286 mil seguidores, tem baixa visibilidade de vídeos e curtidas por postagens. O vídeo com maior visibilidade da amostra teve 7.666 mil visualizações e o post com maior número de curtidas teve 4.031 likes. Cabe lembrar que a curtida requer uma ação do seguidor/usuário, que preenche um coração validando a imagem, e o vídeo contabiliza as visualizações de quem viu o conteúdo (independente de curtir). Para temáticas fora da pesquisa, como vacinação, há vídeos com mais de 50 mil visualizações (individualmente).

O volume das postagens sobre amamentação diminuiu em 2018. Considerando o mês de agosto, que é o mês com mais postagens nas duas amostras - pelo Agosto Dourado -, identificou-se uma queda de $44 \%$ nas postagens. Isso impacta diretamente a atividade, pois reduz a frequência das atualizações. A diminuição reflete também o número de curtidas e comentários no mesmo período, como ilustra o Quadro 2:

Quadro 2 - Postagens em agosto sobre amamentação no Instagram do MS

\begin{tabular}{|l|l|}
\hline $\mathbf{2 0 1 7}$ & $\mathbf{2 0 1 8}$ \\
\hline Posts: 25 & Posts: 11 \\
\hline Curtidas: 20.339 & Curtidas: 11.963 \\
\hline Comentários: 425 & Comentários: 258 \\
\hline
\end{tabular}

Fonte: A autora (2018).

É importante destacar que, mesmo com a Lei Agosto Dourado, sancionada em 2017, houve uma redução de posts sobre o tema, em 2018, no mês em questão. A legislação prevê a conscientização e esclarecimento sobre a amamentação e divulgação nas diversas mídias em agosto. Essa desvalorização do espaço de diálogo no Instagram é incoerente com a função de apoio do MS na Estratégia Nacional para Promoção do Aleitamento Materno e Alimentação Complementar Saudável no SUS - Estratégia Amamenta e Alimenta Brasil, instituída em 2013, e na Política Nacional de Promoção, Proteção e Apoio ao Aleitamento Materno.

O engajamento do perfil do Ministério da Saúde foi impactado não só pela redução de postagens, mas pela falta de diálogo do perfil oficial com seus seguidores. Há na amostra diversos posts que geraram comentários dos usuários e não houve um retorno oficial do Ministério. Essa falta de diálogo reduz possibilidades de engajar os usuários. Recuero destaca as consequências desta conduta para as redes: "O que acontece com muitas marcas é que elas jamais conversaram com seus consumidores. Com isso, não há relacionamento [...] um pouquinho de atenção já descomplicaria uma série de crises. E já constrói um pouquinho mais de capital social e relacionamento entre consumidor e marca"22.

Os temas privilegiados no conteúdo do Instagram do MS reproduzem os conteúdos expostos em documentos técnicos produzidos pelo órgão: "Pesquisas apontam que o leite materno, além de proteger a criança pequena contra diarreias, pneumonias, infecções de ouvido e alergias, propicia melhor desenvolvimento do sistema nervoso, forte vínculo com a mãe e menor chance de desenvolverem diabetes, obesidade, hipertensão arterial e vários tipos de câncer na vida adulta [...]. A amamentação também proporciona diversos benefícios para as mães, entre eles destacam-se a maior facilidade de perder peso após a gestação e a prevenção do câncer de mama durante e após o período de aleitamento"19.

Predominam postagens sobre a amamentação de crianças, com informações direcionadas aos cuidados dos bebês. A mãe e a saúde da mulher são citadas diretamente em 10 posts (15\% da amostra), de forma secundária. As dificuldades das mulheres de amamentar também foram destacadas. O segundo post com maior interação da amostra (com 2.088 curtidas e 56 comentários) falava da mastite (inflamação na mama). $\mathrm{Na}$ amostra, os pais foram citados em apenas um post (no dia dos pais em 2017) e os 'familiares, vizinhos e amigos' são citados como apoiadores em outro post. 
Esse desequilíbrio entre os atores é descrito por Kalil e Aguiar ${ }^{23}$ como temas negligenciados nos conteúdos de orientação ao aleitamento materno: a) perspectivas da mulher no processo de amamentação; b) amamentação e paternidade; e c) o desmame como transição necessária. As autoras mapearam os silêncios nos discursos pró-aleitamento, a partir de uma análise de gênero: "No caso brasileiro, a análise dos materiais nos permitiu identificar que, ainda hoje, a maior parte desses discursos continua a enfatizar a importância da prática para a saúde da criança, enfocando-a sob a ótica do 'aleitamento materno' (provimento de leite ao bebê) em detrimento da 'amamentação' (processo intersubjetivo complexo com potenciais desdobramentos psíquicos e sociais para os envolvidos) [...] Prevalece a visão de uma relação predominantemente instrumental: cabe à mulher fornecer ao/a seu/sua filho/a o melhor alimento, ao mesmo tempo seguro, mais completo do ponto de vista nutricional e com valor imunológico inestimável. A mãe é persuadida a amamentar com base, sobretudo, na publicização dos atributos do leite materno e seu caráter supostamente indispensável à saúde da criança. Não se trata de desqualificar a importância da amamentação, mas de problematizar como os discursos naturalizam a prática, reduzindo-a a comportamentos eminentemente biológicos que definiriam o papel natural da mulher na sociedade. Tal situação implica a valorização ou destaque de determinados sentidos em detrimento de outros, temporariamente apagados ou ofuscados. A amamentação como experiência complexa é pouco explorada, o que nos ajuda a compreender o contexto em que o desmame é um processo de transição silenciado"²3.

No material coletado, não foram observados posts orientando mães e respectivas famílias sobre o fim da amamentação. Apenas dois posts falaram do aspecto da nutrição da alimentação da criança após os seis meses de idade, enfatizando a necessidade de continuar a ser amamentada. As mulheres não receberam atenção necessária, não tiveram suas demandas atendidas em totalidade, como parte fundamental do processo da amamentação. Kalil e Aguiar sugerem ao MS que incluam a mulher como protagonista na prática da amamentação em conteúdos sobre o tema.

As mulheres e as mães interessadas no diálogo sobre aleitamento materno formam uma comunidade virtual ativa ${ }^{24}$ na internet. E o diálogo com este grupo fortaleceria o engajamento sobre o conteúdo do MS nas redes. Lemos $^{25}$ descreve esse tipo de comunidade como agregações em torno de interesses comuns, independentes de fronteiras ou demarcações territoriais fixas. Elas são formadas naturalmente por consumidores dentro de fronteiras que eles mesmos definem e permitem a entrada de instituições nas quais confiam ${ }^{10}$.

Para Martino ${ }^{26}$, a força dessas comunidades é justamente a interação humana que, mesmo ocorrendo virtualmente, mobiliza afetos, vontades e conhecimento compartilhado. $\mathrm{O}$ autor destaca a reciprocidade como um princípio na economia das comunidades virtuais. Tendo em vista essas perspectivas, a estratégia de não dialogar com essas comunidades de forma eficiente torna as ações do MS no Instagram frágeis.

Esse silêncio do MS é reforçado quando os posts que marcam o conteúdo do órgão são observados. Há uma aba que expõe as postagens que marcam o perfil do MS e nelas não há uma interação do órgão com o post feito por seguidores. Não tivemos acesso às interações possivelmente feitas no canal de mensagens diretas do perfil. Mas a partir do que foi exposto, é necessário ampliar o diálogo com a população e inserir o seguidor como cogestor do conteúdo produzido.

Quanto à influência, observou-se que o perfil oficial de saúde foi usado por perfis de profissionais de saúde (pediatras, enfermeiros etc.), usuários e influenciadores digitais como fonte oficial de conteúdo sobre o tema. Os chamados reposts com o conteúdo do Ministério da Saúde no Instagram reforçam a sua importância na rede. Apesar da falta de diálogo direto com os usuários, podemos considerar o perfil do MS influente pelo seu papel institucional.

Considerando as estratégias de posicionamento nas redes sociais direcionadas pelo Marketing 4.0, observa-se que o Ministério da Saúde usa as redes para produção de conteúdo com uma agenda de saúde - impactando a vida online e offline dos seguidores. Amplia a visibilidade do órgão pelo Instagram, mas os indicadores de número de comentários e curtidas apontam que ele não consegue uma mobilização capaz de gerar uma defesa da instituição, os chamados advogados da marca. 
Uma das possibilidades é a falta de humanização da imagem do Ministério no perfil analisado, que opta por uma fala super institucionalizada e não tem um diálogo com seguidores. A estratégia de relacionamento apresenta um viés verticalizado, em detrimento da horizontalidade pregada na nova era de relacionamento do marketing na rede. Poucos posts convidam à interação, com perguntas e convites de engajamento via hashtags. O MS interagiu (via repost) pouco com as ações dos internautas com o conteúdo de seu perfil. Esse posicionamento destoa das recomendações dadas pelo manual da Secom. Outra questão relevante diz respeito à baixa representação da diversidade das mulheres brasileiras nas imagens, focando em mulheres brancas, urbanas e de classe média. Apenas a madrinha da campanha de 2018, Sheron Menezzes, apareceu representando as mães negras nos posts em um ano. Mães indígenas, do campo e de outras representações não estavam presentes nas imagens. Essa falta de pluralidade reduz a possibilidade de personalização do conteúdo, e pode implicar na diminuição de empatia nas mulheres.

\section{Considerações finais}

A internet tem assumido um protagonismo no cenário midiático brasileiro, apesar de não haver um acesso universal. Desde a lei do Marco Civil da Internet, em 2014, é considerada como um direito do cidadão, por interferir diretamente no exercício da sua cidadania. Esse espaço é estratégico para analisar a produção de informações, de diálogos e de sentidos sobre saúde, a partir de órgãos governamentais, com a sociedade. Por se tratar do perfil oficial de saúde do governo federal, o perfil do Ministério da Saúde é o espaço privilegiado de observação dessas interações e de questionamento das práticas.

A exposição do tema do aleitamento materno no Instagram do Ministério da Saúde é uma ação de marketing social e digital que fortalece a Política Nacional de Promoção, Proteção e Apoio ao Aleitamento Materno no país. Esta tem como objetivos específicos produzir e difundir conhecimentos sobre aleitamento materno além de protegê-lo do marketing não ético de produtos industrializados que competem com a amamentação.

O estudo de caso realizado identificou uma redução de conteúdo e a falta de interação com seguidores nesse canal segmentado, que fala diretamente com as mulheres interessadas na temática. Isso enfraqueceu o diálogo com as usuárias do SUS, cidadãs com direito à informação (sobre sua saúde, corpo e vida), a respeito de um tema que impacta a sua realidade e de toda a família - a amamentação. Além de fragilizar o papel de articulador do órgão junto às políticas de promoção do aleitamento, sobretudo nas redes sociais, onde é expressivo o marketing das indústrias de alimentos e produtos para competirem com ele.

Os silêncios encontrados na amostra, a diminuição do diálogo, a falta de interação em canais oficiais de saúde revelam a perspectiva verticalizada da produção de informação sobre a amamentação. Kalili26 constatou esta realidade na produção de material técnico do MS sobre o tema e sugere algo que pode ser aplicado ao conteúdo das redes sociais, no caso, no Instagram: “[...] as ações de comunicação e saúde em uma perspectiva mais ampla e integradora de diversos saberes - inclusive das próprias mulheres/mães e suas famílias - na educação voltada para o sucesso de amamentação só poderá se constituir por meio de uma "atitude de escuta" das diversas vozes envolvidas nesse processo comunicacional e por uma percepção mais ampla da mulher enquanto lactante". Esta percepção permitirá a construção de uma atitude e um modelo de comunicação e saúde capaz de ouvir antes de aconselhar ${ }^{26}$.

Neste artigo, acompanhou-se a produção de conteúdo para um perfil específico de usuárias do Instagram, mulheres e mães que tenham interesse no aleitamento materno. No contexto de uma ação de marketing social e digital (com propagação de conteúdos que estimulem a amamentação, tirem dúvidas sobre como amamentar, falem da importância do leite materno para a saúde das crianças, e das ações de engajamento de seguidores), constatou-se que foi feito conteúdo institucional que impactou a vida das pessoas nas redes e fora dela. Contudo, o Ministério da Saúde não conseguiu advogadas da marca para o órgão. Apesar de ser o principal órgão oficial, tem 286 mil seguidores, e no tema selecionado, observou-se uma baixa visibilidade 
de vídeos, baixo número de curtidas por postagens e um número baixo de comentários por publicação. Em 2017, os posts somaram 517 comentários e, no ano seguinte, 33 posts geraram 774 comentários.

O Quadro 3 expõe a análise de conteúdo feita, por meio das métricas de monitoramento, considerando o tópico da amamentação, comparando os dados mapeados em 2017 e 2018.

Quadro 3 - Síntese do monitoramento do Instagram do MS relacionado à amamentação

\begin{tabular}{|c|c|}
\hline Alcance: Baixo & Volume: Diminuiu \\
\hline 286 mil seguidores & 2017: 32 posts em 4 meses \\
\hline $\begin{array}{l}\text { Baixa visualização de vídeos da temática } \\
\text { vídeo com maior visualização: } 7.666\end{array}$ & $\begin{array}{l}\text { 2018: } 33 \text { posts em } 6 \text { meses } \\
45 \% \text { dos posts (15) sobre a doação do leite }\end{array}$ \\
\hline $\begin{array}{l}\text { Baixo número de curtidas por posts } \\
\text { post com maior número de curtidas: } 4.031\end{array}$ & \\
\hline Atividade: Diminuiu & Engajamento: Baixo \\
\hline $\begin{array}{l}\text { Agosto de 2017: } 25 \text { posts/20.339 curtidas } \\
\text { Agosto de 2018: } 11 \text { posts/11.963 curtidas }\end{array}$ & $\begin{array}{l}\text { Post com perguntas de seguidores sem resposta; } \\
\text { Reposts feitos nos perfis de seguidores sem ação do MS } \\
\text { (comentário e ou curtida); } \\
\text { Reposts feitos na página do MS apenas de celebridades. Não } \\
\text { mostrou mulheres não céelebres; } \\
\text { Baixa quantidade de comentários; } \\
\text { Poucos convites para uso de hashtags sobre posts do MS. }\end{array}$ \\
\hline \multicolumn{2}{|l|}{ Influência: Baixa } \\
\hline \multicolumn{2}{|c|}{$\begin{array}{l}\text { - A principal referência de saúde do Brasil na rede social, contudo, não dialoga com usuários/seguidores } \\
\text { diretamente na rede; } \\
\text { - No tema da amamentação não observamos um diálogo com comunidades virtuais para ampliar o } \\
\text { alcance das mensagens e o engajamento dos seguidores; } \\
\text { - A disseminação de conteúdo ainda é baixa, tendo em vista os indicadores apontados. Isso impacta as } \\
\text { estratégias de marketing social que estimulam adoção hábitos e ou mudança de comportamento. No } \\
\text { caso estudado, promove uma mobilização parcial a favor da amamentação. }\end{array}$} \\
\hline
\end{tabular}

Fonte: A autora (2018).

O Ministério da Saúde não estabeleceu uma relação humanizada com a comunidade de mulheres (mães, avós, tias, madrinhas, amigas etc.) que estimulem a amamentação de crianças. Uma das principais possibilidades foi o predomínio de uma fala institucional, com conteúdo verticalizado, sem a personalização indicada no Marketing 4.o para gerar uma empatia com o público; há falta de diálogo com as seguidoras nos comentários e nos reposts com marcação do Ministério. Percebeu-se uma redução no engajamento, com diminuição dos comentários. Em 2017, 40\% dos posts tiveram até 10 comentários. Em 2018, 51\% dos posts tiveram até 10 comentários. A redução de postagens sobre amamentação, em 2018, também enfraqueceu o engajamento; outro fator relevante foi a falta de diversidade na representação das mães nas imagens, priorizando um perfil urbano, de mulheres brancas e de classe média.

A falta de relacionamento com a comunidade destacada nesta pesquisa aponta a necessidade de o Ministério da Saúde ampliar as estratégias de diálogo, incluindo as demandas do cidadão, que passou, 
nas últimas décadas, a ter uma participação ativa nas relações sobre a saúde, após as ferramentas de participação do SUS. Esta prática dialógica ${ }^{1}$ deve ser levada às redes sociais, considerando a influência dessas novas mídias na vida das pessoas. O MS precisa incluir o cidadão não apenas como alvo do conteúdo, mas como um interlocutor e coautor de conteúdo. É necessário conversar, responder às dúvidas, incluir questões propostas pelos usuários, expor a diversidade da população nas imagens e manter um volume de postagens crescentes para gerar uma mobilização em torno dos temas propostos nas redes sociais. Este engajamento é estratégico para ampliar o conhecimento sobre a saúde, sobre campanhas e tornar o cidadão mais consciente da sua saúde e da sociedade na qual está inserido.

\section{Referências}

1. Lemos A, De Sena C. Mais livre publicar: efemeridade da imagem nos modos galeria e stories do Instagram. Mídia Cotidiano [Internet]. 2018 ago [citado 19 set 2018];12(2):6-26. Disponível em: http:// periodicos.uff.br/midiaecotidiano/article/view/10035/8493.

2. $\quad$ Araújo IS, Cardoso JM. Comunicação e Saúde. Rio de Janeiro: Editora Fiocruz; 2007.

3. Instituto Brasileiro de Geografia e Estatística [Internet]. Pesquisa Nacional por Amostra de Domicílios (PNAD); 2016[citado 11 ago 2017]. Disponível em: https://www.ibge.gov.br/estatisticas-novoportal/ sociais/trabalho/17270-pnad-continua.html?=\&t=0-que-e.

4. Relatório Final Pesquisa Brasileira de Mídia - PBM 2016 [Internet]. Portal Secom; 2018 [citado 27 out 2018]. Disponível em: http://www.secom.gov.br/atuacao/pesquisa/lista-de-pesquisas-quantitativas-equalitativas-de-contratos-atuais/pesquisa-brasileira-de-midia-pbm-2016.pdf/view.

5. Presidência da República (BR), Secretaria-Geral, Subchefia para Assuntos Jurídicos. Lei no 13.435 de 12 de abril de 2017. Institui o mês de agosto como o Mês do Aleitamento Materno. DOU [Internet]. 13.04.2017 [citado em 8 set. 2018]. Disponível em: http://www2.camara.leg.br/legin/fed/lei/2017/lei13435-12-abril-2017-784611-publicacaooriginal-152356-pl.html.

6. Kunsch MMK. Planejamento de relações públicas na comunicação integrada. 6. ed. São Paulo: Summus; 2016.

7. Schneider G, Luce FB. Marketing social: abordagem histórica e desafios contemporâneos. Rev Bras Marketing [Internet]. 2014 [citado em 8 set. 2018]:13(3):125-137. Disponível em: http://www. revistabrasileiramarketing.org/ojs-2.2.4/index.php/remark/article/view/2728/2158. Doi: 10.5585/remark. v13i3.2728.

8. Paula MV, Tarabai NK, Souza G. Marketing social: a evolução dos estudos no Brasil. Rev Bras Pesquisas Marketing Opinião Mídia [Internet]. 2017 set [citado 25 out 2018];10(3):344-57. Disponível em: http:// www.revistapmkt.com.br/Portals/9/Revistas/v10n3/5\%20-\%20Marketing\%20social\%20-\%20A\%20 evolu\%C3\%A7 0\%20dos\%20estudos\%20no\%20Brasil.pdf.

9. Pereira NA, Barbosa L, Silva A, Dantas M. O paciente informado e os saberes médicos: um estudo de etnografia virtual em comunidades de doentes no Facebook. Hist Ci Saúde Manguinhos [Internet]. 2015 dez [citado 20 out 2018];25(suppl):1653-71. Disponível em: http://www.scielo.br/pdf/hcsm/ v22s0/0104-5970-hcsm-22-s1-1653.pdf.

10. MS lança perfil no Instagram [Internet]. Blog da Saúde. 2013 [citado 21 ago 2018]. Disponível em: http://www.blog.saude.gov.br/31897-ministerio-da-saude-lanca-perfil-no-instagram.

11. Kotler P, Kartajaya H, Setiawan I. Marketing 4.0 do tradicional ao digital. Rio de Janeiro: Sextante; 2017.

12. Manual de Orientação para Atuação em Mídias Sociais Identidade Padrão de Comunicação Digital do Poder Executivo Federal [Internet]. Portal Secom; 2018 [citado 27 out 2018]. Disponível em: http:// www.secom.gov.br/pdfs-da-area-de-orientacoes-gerais/internet-e-redes-sociais/diretrizes-comunicacaodigital-governo-federa-jan2014.pdf-1/view.

13. Facebook [Internet]. Facebook do Ministério da Saúde; 2018 [citado 1 set 2018]. Disponível em: https:// www.facebook.com/minsaude/.

14. Instagram [Internet]. Instagram Press; 2018 [citado em 2018 set. 1]. Disponível em: https://instagrampress.com/. 
15. Kalil IR. De silêncio e som: a produção de sentidos nos discursos oficiais de promoção e orientação ao aleitamento materno brasileiro [tese]. Rio de Janeiro: Fundação Oswaldo Cruz; 2015 [citado 11 out 2018 out 11]. Disponível em: https://www.arca.fiocruz.br/handle/icict/11825.

16. Sibilia P. O Show do Eu. Rio de Janeiro: Nova Fronteira; 2008. Instagram [Internet].

17. Instagram do Ministério da Saúde; 2018 [citado em 2018 set. 1]. Disponível em: https://www. instagram.com/minsaude/?hl=pt-br.

18. Bases para a discussão da Política Nacional de Promoção, Proteção e Apoio ao Aleitamento Materno [Internet]. Biblioteca Virtual em Saúde do Ministério da Saúde; 2017 [citado 30 out 2018]. Disponível em: http://bvsms.saude.gov.br/bvs/publicacoes/bases discussao politica aleitamento materno.pdf.

19. Estratégia Nacional para Promoção do Aleitamento Materno e Alimentação Complementar Saudável no Sistema Único de Saúde: manual de implementação [Internet]. Biblioteca Virtual em Saúde do Ministério da Saúde; 2015 [citado 30 out 2018]. Disponível em: http://bvsms.saude.gov.br/bvs/publicacoes/ estrategia nacional promocao aleitamento materno.pdf.

20. Silva T, Cerqueira R. Mensuração em mídias sociais: quatro âmbitos de métricas. In: Chamusca M., Carvalhal M, organizadores. Comunicação e marketing digitais: conceitos, práticas, métricas e inovações. Salvador (BA): Edições VNI; 2011. p. 119-41.

21. Recuero R. Redes sociais na Internet. Porto Alegre: Sulina; 2009.

22. Recuero R. Curtir, compartilhar, comentar: trabalho de face, conversação e redes sociais no Facebook. Verso Reverso. 2013 [citado 28 set 2018];28(68):114-124. Disponível em: http://www.revistas.unisinos. br/index.php/versoereverso/article/viewFile/7323/4187. doi: 10.4013/ver.2014.28.68.06.

23. Kalil IRK, Aguiar AC. Silêncios nos discursos pró-aleitamento materno: uma análise na perspectiva de gênero. Rev Estud Fem [Internet]. 2017 maio [citado 28 out 2018]; 25(2):637-60. Disponível em: http://www.scielo.br/scielo.php?pid=S0104-026X2017000200637\&script=sci abstract\&tlng=pt.

24. Medrado A, Muller AP. Ativismo digital materno e feminismo interseccional: uma análise da plataforma de mídia independente "Cientista que virou mãe". Braz Journal Res [Internet]. 2018 abr [citado 15 out 2018];14(1):184-211. Disponível em: https://bjr.sbpjor.org.br/bjr/article/viewFile/1055/pdf 1 .

25. Lemos A. Cibercultura: tecnologia e vida social na cultura contemporânea. Porto Alegre: Sulina; 2004.

26. Martino LMS. Teoria das mídias digitais: linguagens, ambientes, redes. Petrópolis, RJ: Vozes; 2014. 